\title{
EFFECT OF HYDROSTATIC PRESSURE ON THERMODYNAMIC PROPERTIES OF NiTI SHAPE MEMORY ALLOY
}

\begin{abstract}
The effect of hydrostatic pressure and different heating/cooling rates on physical properties and microstructure of NiTi shape memory alloy has been investigated. The transformation temperatures and physical properties of the alloy have changed with applied pressure. It has been clearly seen from Differential Scanning Calorimetry (DSC) that with the increase of applied pressure, while $A_{s}$ and $A_{f}$, and $M_{f}$ transformation temperatures decrease, $M_{s}$ value increase. Moreover, based on the increase of the pressure amount applied on the sample, there was an average increase of $48 \%$ for Gibbs free energy and $18 \%$ for elastic strain energy. Entropy of the alloys decreases depending on the increase in the amount of applied pressure for all heating rates. Depending on the amount of applied pressure on the sample, an interior strain of $0.177 \%$ at most was observed. With the increase of applied pressure on the sample, it was determined that activation energy increased. Additionally, the Scanning Electron Microscopy (SEM) images of the samples show that the grain sizes of the unpressured sample and the samples on which pressure is applied are between 40 and 120 $\mu \mathrm{m}$, which was determined by Image Analysis Method.

Keywords: Shape Memory Alloy, Phase Transformation, Differential Scanning Calorimetry, Electron Microscopy, Gibbs Free Energy, Activation Energy
\end{abstract}

\section{Introduction}

In recent years shape memory alloys (SMAs) have been recognized as effective and promising means for application in various branches of engineering, e.g. space technology, medicine, robotics and actuator technology [1]. Ni-Ti-based alloys are the most important practical shape memory alloys (SMA) with excellent mechanical properties. Many investigations focus on their unusual material characteristics: shape memory effect and pseudo elastic behavior [2-4]. Martensite and austenite transformations occur in certain critical temperatures. On cooling the sample in austenite phase, the formation of martensite starts at a temperature $M_{s}$ and then the transformation is completed at a temperature $M_{f}$, forward transition A(Austenite) ${ }^{\circledR} \rightarrow$ $\mathrm{M}$ (Martensite). In case on heating the sample in martensite state, formation of austenite starts at temperature $A_{s}$ and then nearly all the martensite transforms to austenite structure at temperature $A_{f}$, reverse transition $\mathrm{M} \rightarrow \mathrm{A}$. These critical temperatures and the released or absorbed energies during forward and reverse transformations characterize the thermodynamic properties of shape memory behavior $[3,5]$. The shape memory effect is created by a diffusionless, reversible transformation between low-temperature martensitic and high-temperature austenitic phases. Transformation from B19', the martensite phase, to B2, the austenite phase, occurs during heating and cooling. These alloys show the ability to dissipate a large fraction of the energy supplied to the system with small plastic deformation, which makes SMAs highly attractive for energy absorption/storage, impact damping or seismic protection [5-7]. The shape memory effect is also related to the martensitic transformation which is essential, and an alloy which exhibits thermoelastic martensitic transition is deformed or bent at a temperature below the martensite finish temperature, $M_{f}$. The commonly adopted form of the Clausius-Clapeyron equation for thermoelastic martensitic transformations is based on the idealized situation where the transformation is complete. The specimen remains in the deformed shape on unloading and recovers the undeformed original shape by heating over the austenite start temperature, $A_{s}$, and regains the deformed shape by recooling below $M_{f}$ [8]. Superelasticity is a stress-induced phase transformation where deformation and recovery are obtained during loading and unloading, respectively, at temperatures above $A_{f}$ [9]. Recently, however, these materials appear promising for civil engineering applications due to the high damping capacity [10-14], coupling with good strength, ductility and very good corrosion resistance. Furthermore, there are many factors, which influence the transformation characteristics in NiTi-based SMAs: the change in nickel content, ageing after solution treatment, thermo-mechanical treatment, thermal cycling, addition of ternary alloying elements and processing techniques [15-18]. Heating rate is another concern in testing SMAs. There are some publications on the thermal and mechanical effects on the transformation behavior of NiTi SMA[19-20].

\footnotetext{
FIRAT UNIVERSITY, FACULTY OF SCIENCES, DEPARTMENT OF PHYSICS, 23169 ELAZIG, TURKEY

Corresponding author: ctatar@firat.edu.tr
} 
The aim of this study is to investigate the influence of pressure and heating rates on physical properties and microstructure of the NiTi shape memory alloy.

\section{Experimental}

The NiTi alloy used in this study was supplied from the memory-Metalle Gmbh, Germany. The nominal composition is $\mathrm{Ni}-44.74 \mathrm{Ti}$ (wt.\%). Six pieces of the sample cut from this alloy were annealed in the $\beta$-phase field for $30 \mathrm{~min}$ at $850^{\circ} \mathrm{C}$ for betasising. It was later rapidly quenched in iced brine in order to form the $\beta$ martensites. After the various hydrostatic pressures were applied on the each piece of the sample at room temperature, the hydrostatic pressures were removed. Before measurement, the calibration of DSC calorimeter was performed for various heating/cooling rates to determine transformation temperatures and other phase transformation parameters using Perkin Elmer Sapphire DSC. The phase transformation parameters, $M_{s}, M_{f}$, $A_{s}$ and $A_{f}$, absorbed energies values during cooling and heating of samples were automatically determined from DSC curves using a Perkin Elmer Sapphire DSC software programming. Furthermore, changes in Gibbs free energies, entropies, and elastic energies were calculated by means of the data acquired with DSC measurements. Activation energies of thermoelastic martensitic transformation were also calculated using two different methods known as Kissinger and Ozawa approaches for non-isothermal transformations. Microstructures of the alloy were observed by Scanning Electron Microscopy (SEM) using a JEOL JSM-7001F.

\section{Results and discussion}

Fig. 1 shows the results of DSC studies of the reference sample and the samples with applied pressure for 5,10,20 and $30^{\circ} \mathrm{C} / \mathrm{min}$ heating/cooling rates. The austenite and martensite transformation temperatures were determined from the DSC curves and are given in Table 1. During heating and cooling, a one-stage transformation is observed, namely, from the martensite (B19') to austenite phase (B2). The martensitic transformation is a diffusionless first order phase transition in crystalline solids, in which atoms move cooperatively [21-22]. The transformation temperatures and absorbed and released energy depending on applied pressure and different heating/cooling rates are shown in Table 1. As seen in Table 1, it is observed that the transformation temperatures absorbed and released energies change due to applied pressure and different heating/cooling rates. The influence on transformation temperatures $A_{s}, M_{s}$ of applied pressure and different heating rates is shown in Fig. 2. Depending on the increase of applied pressure, $M_{S}$ temperature increased whereas $A_{s}$ temperature decreased. Moreover, it is obvious in Table 1 that, in all DSC measurements taken for different heating/cooling rates, while $M_{s}$ transformation temperature

TABLE 1

The reverse and forward transformation temperatures and the absorbed $\left(\Delta H_{H}\right)$, and released $\left(\Delta H_{C}\right)$ energies obtained from the different heating/cooling curves in Fig. 1

\begin{tabular}{|c|c|c|c|c|c|c|c|c|c|}
\hline Rate $\left({ }^{\circ} \mathrm{C} / \mathrm{min}\right.$.) & Pressure (MPa) & $A_{s}\left({ }^{\circ} \mathrm{C}\right)$ & $A_{p}\left({ }^{\circ} \mathrm{C}\right)$ & $A_{f}\left({ }^{\circ} \mathrm{C}\right)$ & $M_{s}\left({ }^{\circ} \mathrm{C}\right)$ & $M_{p}\left({ }^{\circ} \mathrm{C}\right)$ & $M_{f}\left({ }^{\circ} \mathrm{C}\right)$ & $\Delta H_{H}(\mathrm{~J} / \mathrm{g})$ & $\Delta H_{C}(\mathrm{~J} / \mathrm{g})$ \\
\hline \multirow{6}{*}{5} & Reference sample & 47.5 & 59.7 & 62.7 & 27.4 & 23.1 & 15.2 & -15.6 & 20.0 \\
\hline & 70 & 46.9 & 57.3 & 62.3 & 33.9 & 22.2 & 14.0 & -13.3 & 16.8 \\
\hline & 140 & 46.6 & 57.5 & 62.0 & 31.6 & 20.4 & 13.0 & -11.7 & 14.5 \\
\hline & 210 & 46.4 & 57.4 & 61.6 & 32.8 & 21.5 & 13.2 & -13.6 & 16.3 \\
\hline & 280 & 45.8 & 55.3 & 59.8 & 36.1 & 21.2 & 11.8 & -11.5 & 14.4 \\
\hline & 350 & 43.9 & 56.3 & 62.7 & 37.1 & 21.1 & 10.5 & -8.32 & 10.7 \\
\hline \multirow{6}{*}{10} & Reference sample & 51.5 & 66.1 & 69.9 & 32.7 & 25.3 & 17.4 & -19.1 & 22.3 \\
\hline & 70 & 44.1 & 60.4 & 69.8 & 35.4 & 23.0 & 7.3 & -14.5 & 15.2 \\
\hline & 140 & 45.6 & 60.1 & 67.5 & 34.3 & 21.0 & 8.4 & -13.6 & 15.6 \\
\hline & 210 & 44.8 & 60.6 & 67.1 & 32.6 & 20.0 & 6.2 & -14.0 & 14.3 \\
\hline & 280 & 45.7 & 59.3 & 66.9 & 35.9 & 18.4 & 5.7 & -13.5 & 13.5 \\
\hline & 350 & 40.6 & 58.2 & 66.1 & 38.3 & 17.6 & 2.8 & -10.6 & 10.5 \\
\hline \multirow{6}{*}{20} & Reference sample & 51.3 & 68.4 & 73.9 & 30.5 & 23.1 & 15.2 & -16.5 & 22.3 \\
\hline & 70 & 46.4 & 62.6 & 71.9 & 32.5 & 21.3 & 9.2 & -10.7 & 16.1 \\
\hline & 140 & 45.4 & 62.1 & 71.1 & 31.7 & 20.8 & 9.9 & -10.3 & 16.1 \\
\hline & 210 & 49.7 & 63.0 & 72.6 & 30.6 & 19.0 & 9.0 & -10.0 & 15.9 \\
\hline & 280 & 45.9 & 60.6 & 68.2 & 32.2 & 19.0 & 8.6 & -8.7 & 14.4 \\
\hline & 350 & 43.3 & 59.3 & 67.6 & 36.3 & 19.2 & 6.9 & -5.5 & 10.7 \\
\hline \multirow{6}{*}{30} & Reference sample & 51.3 & 69.3 & 76.5 & 28.1 & 21.2 & 13.2 & -15.2 & 21.8 \\
\hline & 70 & 48.4 & 65.2 & 75.7 & 31.1 & 20.0 & 11.1 & -9.9 & 16.3 \\
\hline & 140 & 48.8 & 64.2 & 74.1 & 31.4 & 19.9 & 10.2 & -9.92 & 16.1 \\
\hline & 210 & 49.6 & 65.3 & 75.7 & 31.0 & 18.9 & 7.5 & -10.0 & 16.3 \\
\hline & 280 & 47.3 & 62.1 & 71.9 & 35.0 & 19.2 & 9.2 & -9.1 & 15.6 \\
\hline & 350 & 46.0 & 60.4 & 71.0 & 34.2 & 19.8 & 9.9 & -5.5 & 10.7 \\
\hline
\end{tabular}




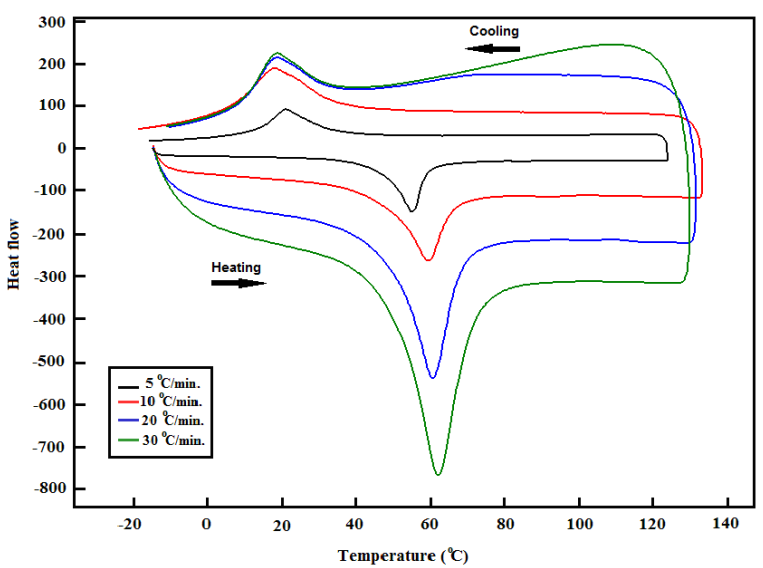

e) $280 \mathrm{MPa}$

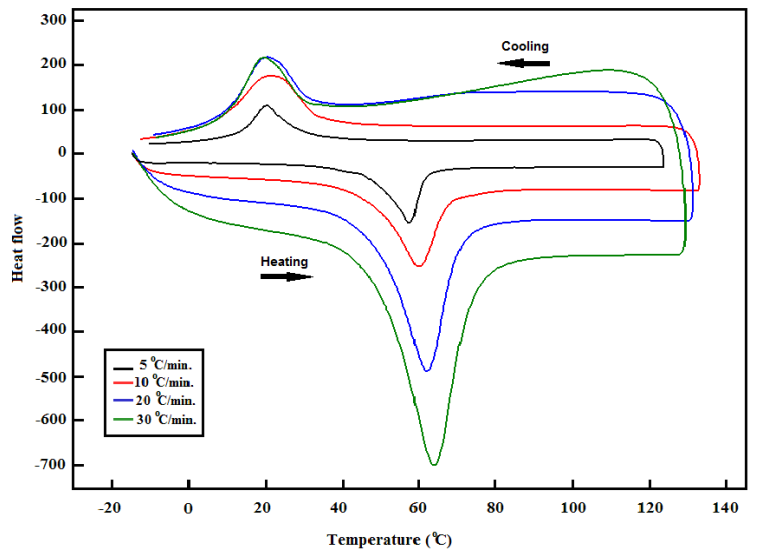

c) $140 \mathrm{MPa}$

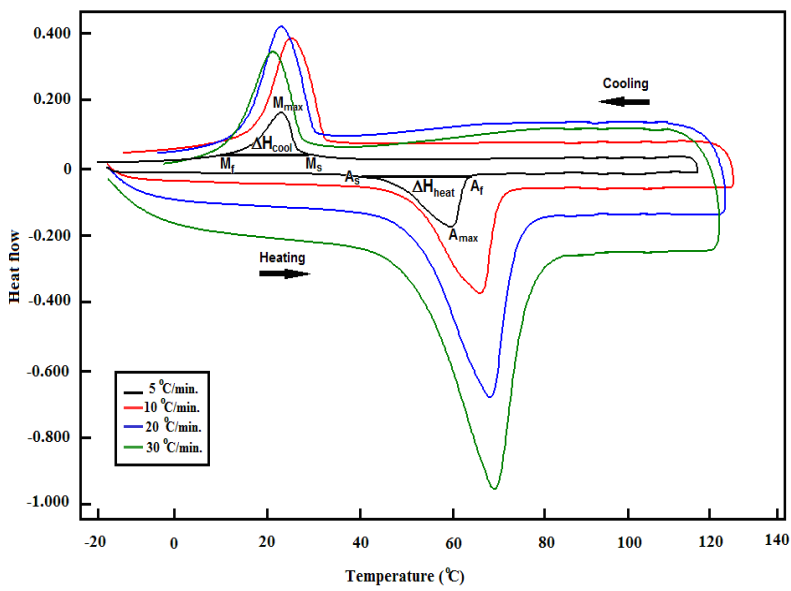

a) reference sample

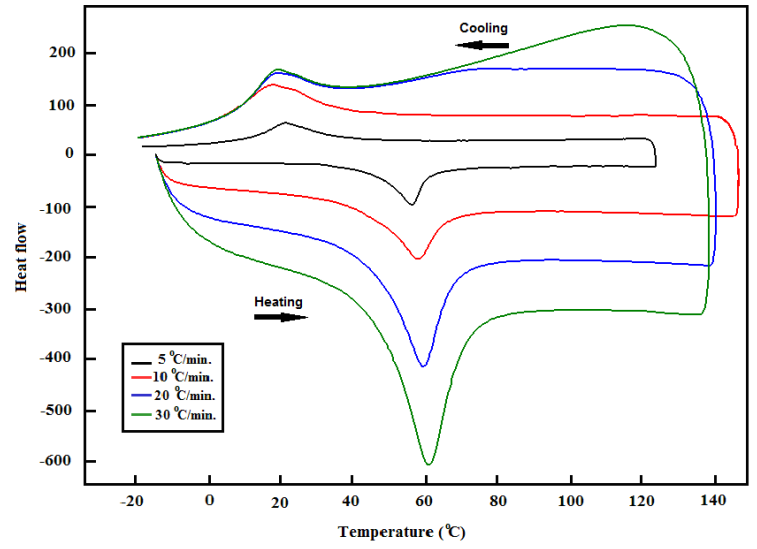

f) $350 \mathrm{MPa}$

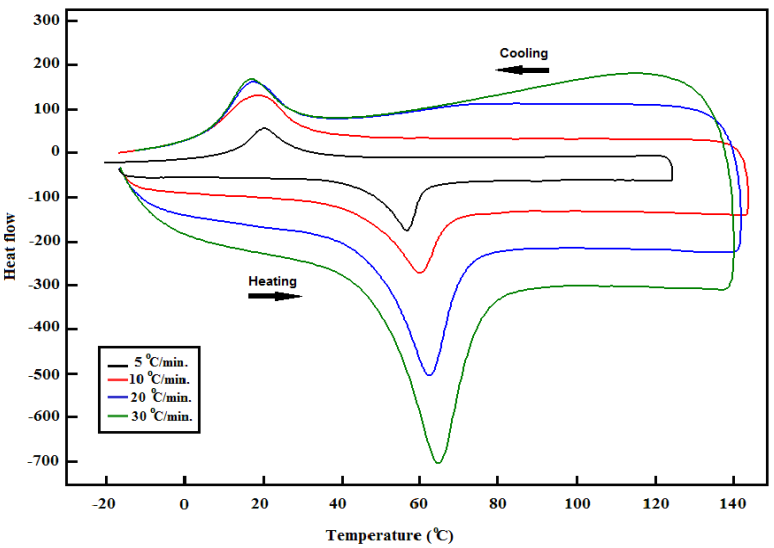

d) $210 \mathrm{MPa}$

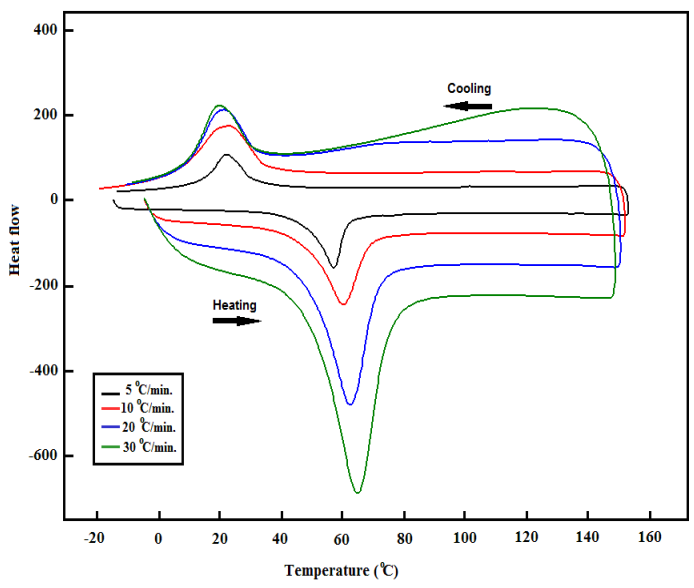

b) $70 \mathrm{MPa}$

Fig. 1. The DSC curves for the heating/cooling rates of 5,10,20 and $30^{\circ} \mathrm{C} / \mathrm{min}$ of samples with reference sample and with applied pressure

increased, $A_{s}, A_{f}$, and $M_{f}$ transformation temperatures decreased, with the increase of the pressure applied on the sample. This determined that the relative phase stability is altered by the applied pressure. This indicates that the increase in pressure has the effect of conversion of more and more residual austenite and furthermore, it has effect of causing large shift in transformation temperatures. The absorbed $\left(\Delta H_{H}\right)$ and released energy $\left(\Delta H_{C}\right)$ values of the alloy by the applied pressure and different heating and cooling rates were determined and are given in
Table. 1 . The decrease in the energy values results in a higher driving force for the reverse transformation. The decrease in the transformation temperatures of the alloys can be explained as follows: The cubic B2 structure in the austenite phase takes place in NiTi-based shape memory alloys. This structural displacement is a result of thermoelastic martensitic transformation. Thermoelastic martensitic transformations develop by three mechanisms: nucleation, growth, and impingement of growing new phase particles $[19,23]$. Furthermore, the Gibbs free ener- 


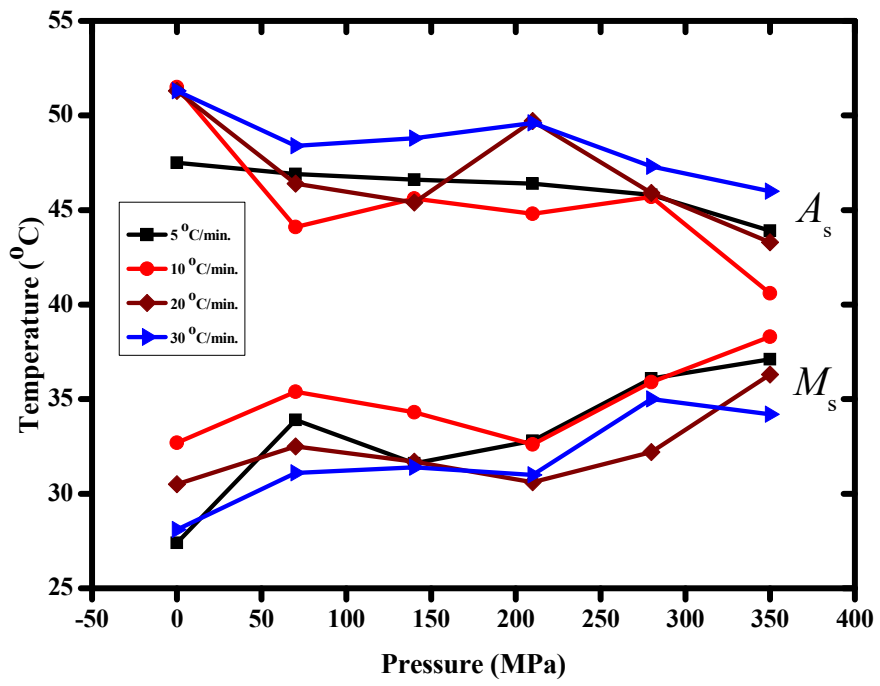

Fig. 2. Variation of transformation temperatures $A_{s}$ versus $M_{s}$ of samples with applied pressure for different heating/cooling rates

gies for austenite phase and martensite phase transformation can be expressed by the following relation $[24,25]$,

$$
\begin{aligned}
\Delta G^{P \rightarrow M} & =\Delta G^{M \rightarrow P}\left(T_{o}\right)-\Delta G^{M \rightarrow P}\left(M_{s}\right) \\
& =-\left(T_{o}-M_{s}\right) \Delta S^{M \rightarrow P}
\end{aligned}
$$

where $T_{o}$ is the equilibrium temperature at which the free energies of martensite and austenite are equal, and is calculated from $T_{o}=\left(A_{f}+M_{s}\right) / 2 . T_{o}$ values for the reference samples and the samples with the applied pressure were calculated using $A_{f}$, $M_{s}$ values determined from DSC measurements and are given in Table 2. It is clearly observed from the calculations that $T_{o}$ values increase with applied pressure. The forward transition enthalpies are obtained by DSC measurements, which are given in Table 1. Once the transformation enthalpies and equilibrium temperatures are determined, the entropies can be calculated by

$$
\Delta S^{M \rightarrow P}=\frac{\Delta H^{M \rightarrow P}}{T_{o}}
$$

$\Delta S^{M \rightarrow P}$ values for samples of calculated from Eq. 2 are given in Table 2. It is clearly shown in Fig. 3 that entropy of the alloys decreases with the increase of pressure applied on the sample. $T_{o}$ values increase with the applied pressure and this suggests that the applied pressure increases the Gibbs free energies of the martensite and austenite phases and in turn, the transformation temperatures increase. Due to the nucleation, growth, and the impingement mechanisms of TMTs, a difference between $M_{s}$ and $M_{f}$ temperatures occur on cooling the specimen, which is related to the elastic energy $\Delta E_{e}$ stored in the self-accommodated martensitic variants. The elastic energy can be calculated by [26]

$$
\begin{aligned}
\Delta E_{e} & =\Delta G^{P \rightarrow M}\left(M_{s}\right)-\Delta G^{P \rightarrow M}\left(M_{f}\right) \\
& =\left(M_{s}-M_{f}\right) \Delta S^{M \rightarrow P}
\end{aligned}
$$

The $\Delta G^{P \rightarrow M}$ and $\Delta E_{e}$ values were determined using Eqs. 1

\begin{tabular}{|c|c|c|c|c|c|c|}
\hline Rate $\left({ }^{\circ} \mathrm{C} / \mathrm{min}.\right)$ & Pressure (MPa) & $T_{o}\left({ }^{\circ} \mathrm{C}\right)$ & $\Delta H^{M \rightarrow P}(\mathrm{~J} / \mathrm{g})$ & $\Delta S^{M \rightarrow P}\left(\mathrm{~J} / \mathrm{g}^{\circ} \mathrm{C}\right)$ & $\Delta G^{P \rightarrow M}(\mathrm{~J})$ & $\Delta E_{e}(\mathrm{~J})$ \\
\hline \multirow{6}{*}{5} & Reference sample & 45.0 & 20.0 & 0.395 & -6.960 & 4.825 \\
\hline & 70 & 48.1 & 16.8 & 0.311 & -4.427 & 6.204 \\
\hline & 140 & 46.8 & 14.5 & 0.279 & -4.254 & 5.206 \\
\hline & 210 & 47.2 & 16.3 & 0.315 & -4.544 & 6.185 \\
\hline & 280 & 47.9 & 14.4 & 0.269 & -3.180 & 6.543 \\
\hline & 350 & 49.9 & 10.7 & 0.188 & -2.410 & 5.008 \\
\hline \multirow{6}{*}{10} & Reference sample & 51.3 & 22.3 & 0.434 & -8.083 & 6.649 \\
\hline & 70 & 52.6 & 15.2 & 0.288 & -4.970 & 8.118 \\
\hline & 140 & 50.9 & 15.6 & 0.306 & -5.086 & 7.935 \\
\hline & 210 & 49.8 & 14.3 & 0.287 & -4.938 & 7.579 \\
\hline & 280 & 51.4 & 13.5 & 0.262 & -4.070 & 7.930 \\
\hline & 350 & 52.2 & 10.5 & 0.201 & -2.795 & 7.139 \\
\hline \multirow{6}{*}{20} & Reference sample & 52.2 & 22.3 & 0.427 & -9.270 & 6.536 \\
\hline & 70 & 52.2 & 16.1 & 0.308 & -6.075 & 7.185 \\
\hline & 140 & 51.4 & 16.1 & 0.313 & -6.170 & 6.827 \\
\hline & 210 & 51.6 & 15.9 & 0.308 & -6.470 & 6.654 \\
\hline & 280 & 50.2 & 14.4 & 0.286 & -5.162 & 6.768 \\
\hline & 350 & 51.9 & 10.7 & 0.206 & -3.215 & 6.059 \\
\hline \multirow{6}{*}{30} & Reference sample & 52.3 & 21.8 & 0.416 & -10.086 & 6.210 \\
\hline & 70 & 53.4 & 16.3 & 0.305 & -6.805 & 6.104 \\
\hline & 140 & 52.7 & 16.1 & 0.305 & -6.507 & 6.476 \\
\hline & 210 & 53.3 & 16.3 & 0.305 & -6.819 & 7.186 \\
\hline & 280 & 53.4 & 15.6 & 0.292 & -5.376 & 7.536 \\
\hline & 350 & 52.6 & 10.7 & 0.203 & -3.742 & 4.942 \\
\hline
\end{tabular}
and 3 and are given in Table 2. It is shown in Fig. 4 that with the increase of different pressure values applied on each sample

The effect of applied pressure on $T_{o}\left({ }^{\circ} \mathrm{C}\right), \Delta H^{M \rightarrow P}(\mathrm{~J} / \mathrm{g}), \Delta S^{M \rightarrow P}\left(\mathrm{~J} / \mathrm{g}^{\circ} \mathrm{C}\right), \Delta G^{P \rightarrow M}(\mathrm{~J})$ and $\Delta E_{e}(\mathrm{~J})$ 


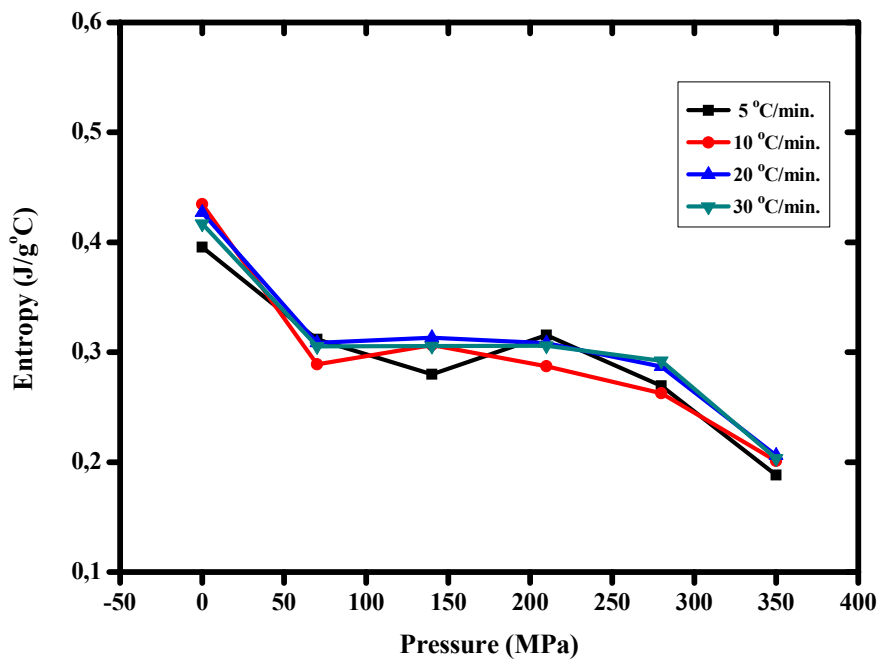

Fig. 3. The variation of $\Delta S^{M \rightarrow P}$ with applied pressure on alloys for different heating rates

for different heating and cooling rates, $\Delta G^{P \rightarrow M}$ values increase whereas a fluctuation around the average value of $\Delta E_{e}$ is observed. Depending on the increase of the pressure amount, there was an average increase of $48 \%, 18 \%$ in Gibbs free energy and elastic energy, respectively. These changes may be due to the stabilization of the martensite phase with respect to the austenite phase. Moreover, the reason for the increase of $\Delta E_{e}$ value with the increase of applied pressure can be explained as follows: While phase transformation is provided with less elastic energy in the reference sample, it is observed that the value of elastic energy is thought to increase in order to eliminate the strain and to provide transformation since strain in alloy increases depending on the pressure. As a matter of fact, elastic energy is a significant feature in the formation of thermoelastic phase transformation. On the other hand, the relationship between pressure and the $A_{s}$, $A_{f}$ transformation temperatures for the alloy can be expressed by the following Clausius-Clapeyron equation [12,27-29]

$$
\frac{d\left(A_{s}\right)}{d \sigma} \approx \frac{\varepsilon^{M \rightarrow P} A_{s}(\sigma)}{\rho \Delta H^{M \rightarrow P}(\sigma)}
$$

where $\varepsilon^{M \rightarrow P}$ is the strain associated with the transformation, $\sigma$ is the pressure, $\rho$ is the density of the alloy, $\Delta H^{M \rightarrow P}$ is the transformation energy. In Eq. $4, \varepsilon^{M \rightarrow P}$ can be obtained from measured values of $\rho, \Delta H^{M \rightarrow P}$ and As. Thus, $\varepsilon^{M \rightarrow P}$ is approximated by the following relation:

$$
\varepsilon^{M \rightarrow P}(\%) \approx 1.68 \frac{A_{s}\left({ }^{\circ} \mathrm{C}\right)-A_{s 0}\left({ }^{\circ} \mathrm{C}\right)}{\sigma(\mathrm{MPa})}
$$

where $A_{s}\left({ }^{\circ} \mathrm{C}\right)$ is the austenite start temperature of the sample with applied pressure and $A_{s 0}\left({ }^{\circ} \mathrm{C}\right)$ is the austenite start temperature of the reference sample. The variation of the strain with pressure is shown in Fig. 5. $\varepsilon^{M \rightarrow P}$ corresponds to the martensite variation formed at the beginning of transformation. It is observed that $\varepsilon^{M \rightarrow P}$ values of the alloy increase with the pressure. This suggests that the increase in pressure has the effect of conversion of more and more residual austenite and furthermore, it

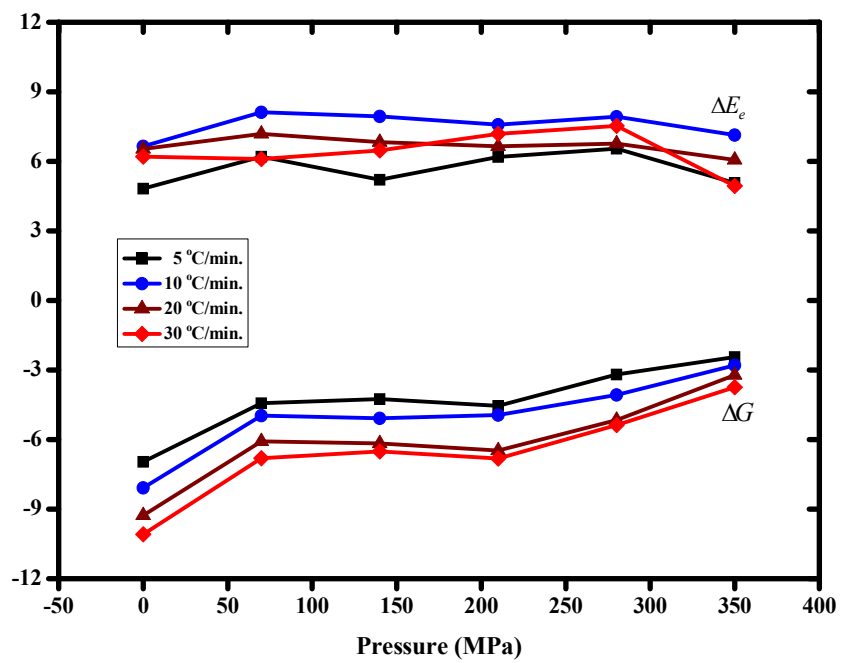

Fig. 4. Plots of $\Delta G^{M \rightarrow P}$ and $\Delta E_{e}$ with applied pressure on the alloy for different heating rates

has effect of causing large shift in transformation temperatures. Additionally, it is clear from Fig. 6 that interior strain of the sample increases with the increase of applied pressure on the sample for four heating/cooling rates. It is seen in Fig. 5 that, among the different pressure amounts applied on the sample, $70 \mathrm{MPa}$ is the pressure with the highest interior strain. In the sample with applied pressure of $70 \mathrm{MPa}$ and $10^{\circ} \mathrm{C} / \mathrm{min}$ heating rate, an interior strain of $0.177 \%$ has occurred. It is clear from Fig. 5 that, with the increase of pressure, the amount of interior strain decreased due to the thermoelastic feature of the sample and the increase of interior response with the applied pressure. Consequently, the lattice change, or the lattice distortion, of the transformation at the atomic level is accumulated and manifested in the shape change of the crystal. In this regard, a thermoelastic martensitic transformation is a mechanical process as well as a thermal transformation process. Owing to this unique combination, specific thermodynamic conditions have been established to express the effects of stress and temperature, as the external driving forces, on the transformation [30].

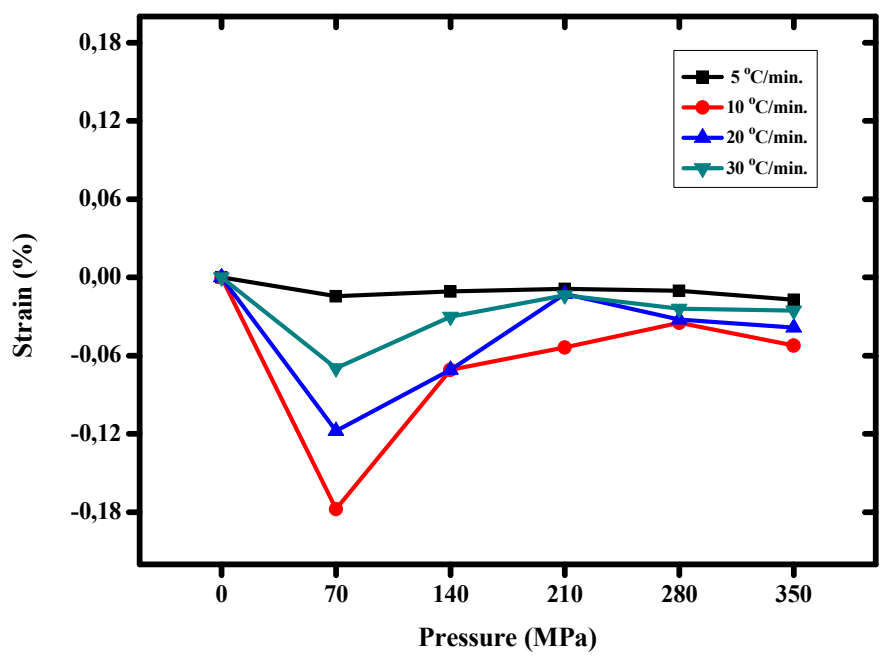

Fig. 5. Strain change with the pressure applied on the sample for different heating rates 


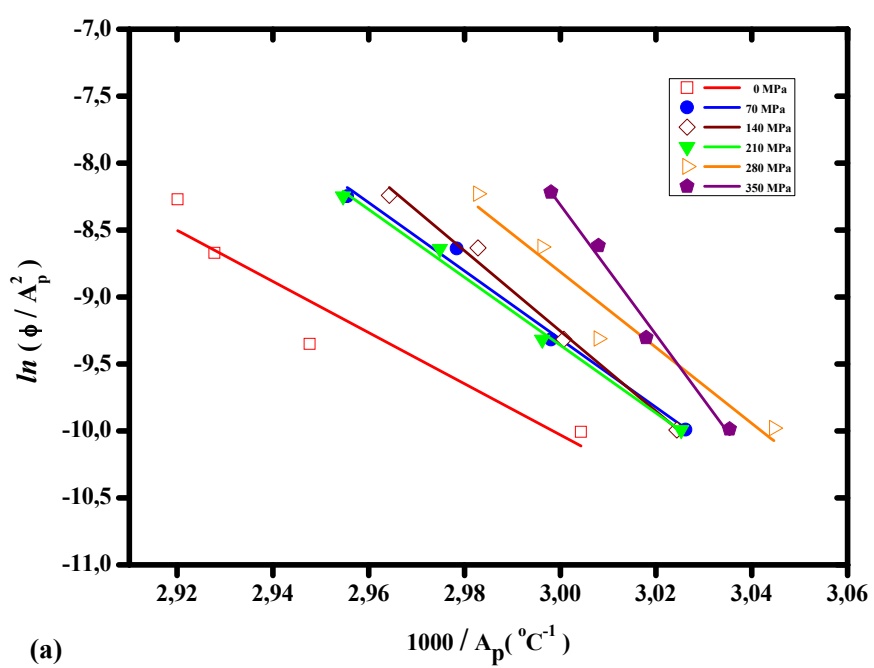

(a)

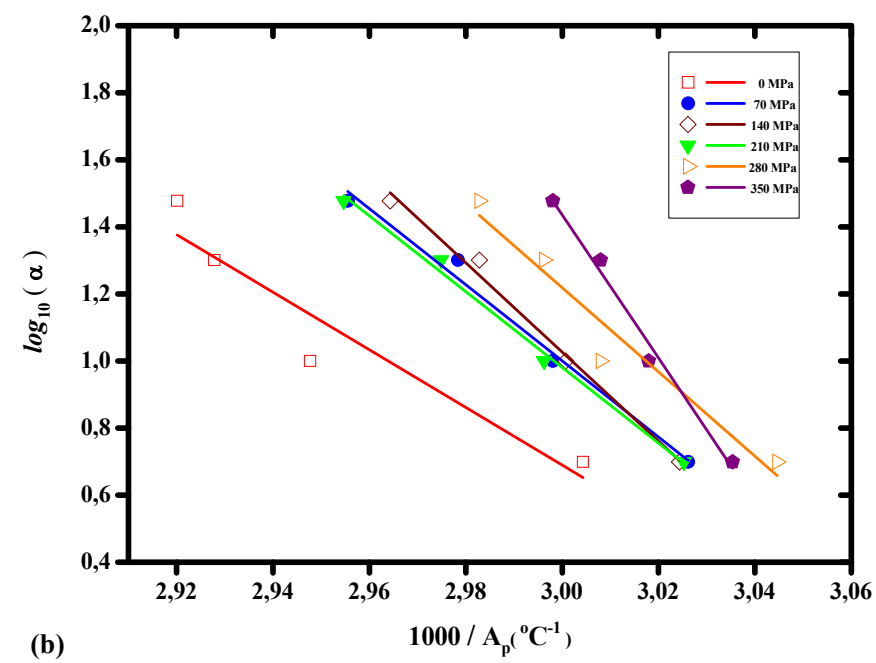

Fig. 6. The fitting curves for (a) Kissinger method and (b) Ozawa method

Besides, the activation energy of phase transformation is also an important parameter in understanding how fast the transformation occurs. The high activation energy reflects the cooperative motion of atoms. Therefore, it can be used to analyze the nucleation and growth mechanisms in TMTs. Kissinger supported that the change in peak temperature with variation of the heating/cooling rate could be used to calculate the activation energy $[19,31]$. According to that approach, the activation energy for phase transformation is given by the following relation,

$$
\frac{d\left(\ln \frac{\phi}{A_{p}^{2}}\right)}{d\left(\frac{1}{A_{p}}\right)}=-\frac{E_{a}}{R}
$$

where $\phi$ is the heating rate in each attempt. $A_{p}$ is the peak temperature of the transformation from martensite to austenite, in units of ${ }^{\circ} \mathrm{C}$ and is given in Table $1 . \mathrm{R}$ is the ideal gas constant and equal to $8.314 \mathrm{~kJ} / \mathrm{mol} .{ }^{\circ} \mathrm{C}$. Thus, the plot of $\ln \left(\frac{\phi}{A_{p}^{2}}\right)$ versus $1 / A_{p}$ gives the slope $-\frac{E_{a}}{R}$ from which the activation energy is calculated. Furthermore, the Ozawa method was calculated to determine the activation energy $[7,19]$. The fitting curves that are used in the calculation of activation energies for both methods are shown in Fig. 6a,b. After these plots, the negative slopes of the straight lines are multiplied by constant $R$ in order to obtain the activation energies. The plots of the calculated activation energies versus applied pressure are shown in Fig. 7. For different pressure values applied on the sample, activation energy changes calculated according to two different methods were in total accordance. While, the activation energy value in the reference sample is $158.72 \mathrm{~kJ} / \mathrm{mol}$, the activation energy value with the pressure of $70 \mathrm{MPa}$ is $211.80 \mathrm{~kJ} / \mathrm{mol}$ and the activation energy value with the pressure of $140 \mathrm{MPa}$ is $249.19 \mathrm{~kJ} / \mathrm{mol}$. Strain occurred in the inner structure of the sample because of the pressure applied on it. Activation energy is needed to eliminate this strain occurring in the alloy in order for phase transformation to start. Therefore, the fact that the necessary activation energy increases with the increase of pressure is clearly seen in Fig. 7. As can be seen in Fig. 8, the microstructures of the alloy changed due to the pressure applied on the sample.

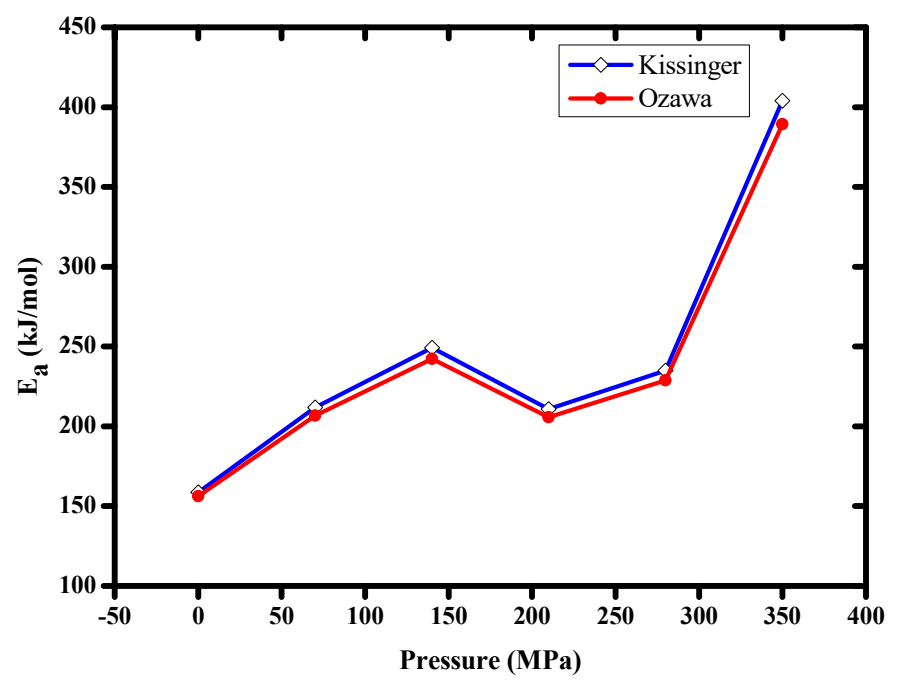

Fig. 7. The change of activation energy versus the pressure of the sample

\section{Conclusions}

The effect of pressure on phase transformation temperature, thermodynamical properties, and microstructure was investigated by applying different values of pressure on NiTi shape memory alloys. The applied pressure causes some changes in austenite and martensite transformation temperatures. An average increase of $48 \%$ for Gibbs free energy and $18 \%$ for elastic strain energy is observed depending on the pressure increase on the sample. Furthermore, the applied pressure occurred on interior strain of $0.177 \%$ in the alloys. The activation energy value is increased with applied pressure. Besides, when Fig. 7 is observed, it is clear that activation energy gets a minimum value at $210 \mathrm{MPa}$ pressure value. The applied pressure changed the microstructure of the alloy. It is evident from SEM images in Fig. 8 that the grain sizes of unpressured samples and samples on which pressure is applied change between 40 and $120 \mu \mathrm{m}$. Besides, martensite laths are clearly observed from the first and second regions in Fig. 8b. 


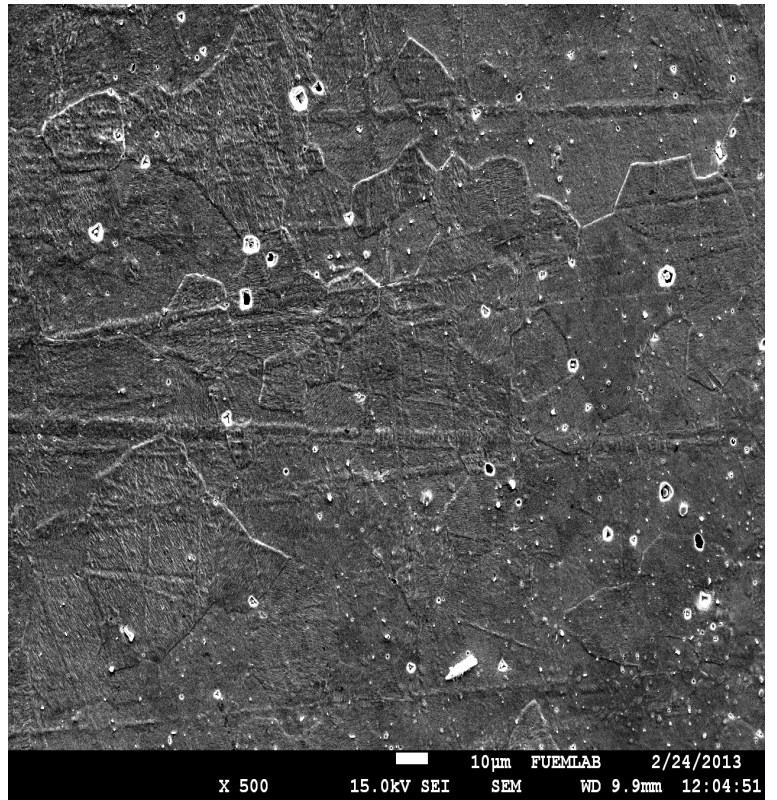

a) reference sample

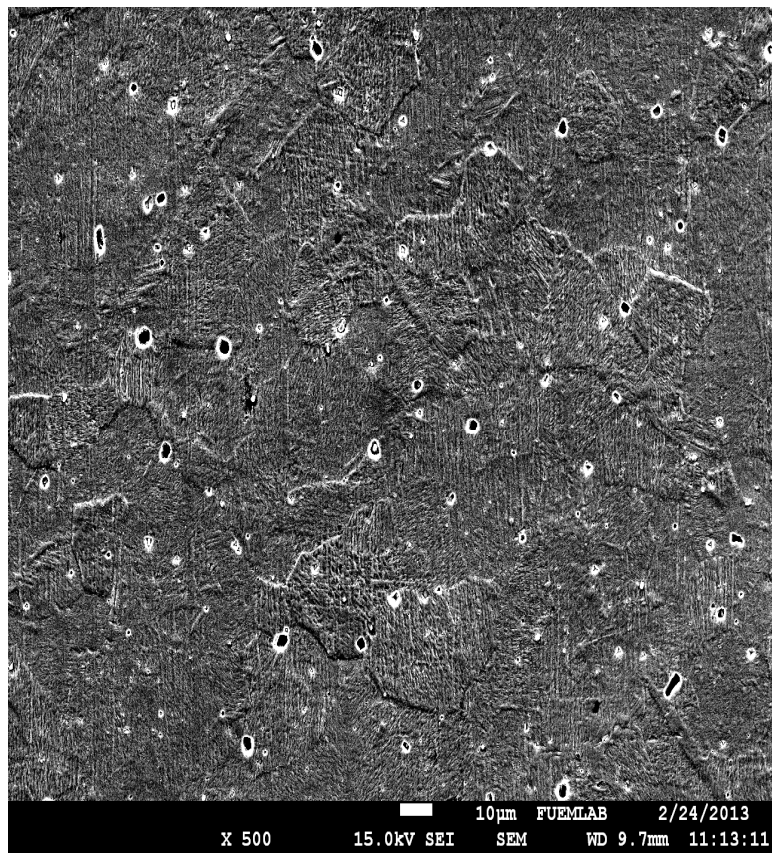

c) $140 \mathrm{MPa}$

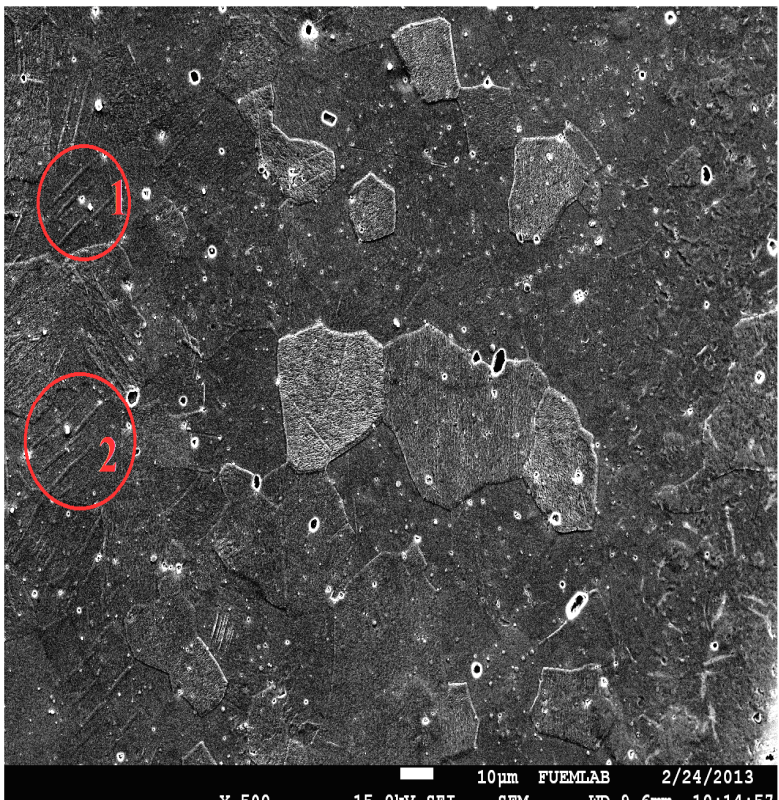

b) $70 \mathrm{MPa}$

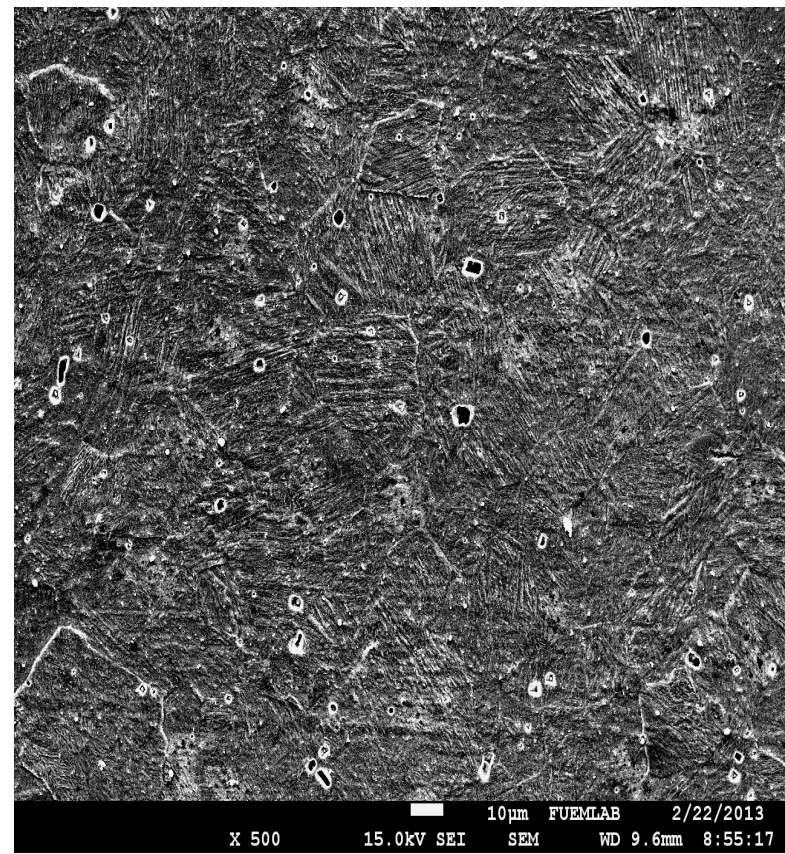

d) $350 \mathrm{MPa}$

Fig. 8. SEM surface images of the reference sample and the samples with different amounts of applied pressure

\section{Acknowledgements}

This work was supported by the Management Unit of Scientific Research projects of Firat University (FÜBAP) (Project Number: FF.13.09)

\section{REFERENCES}

[1] K. Mehrabi, M. Bruncko, A.C.J. Kneissl, J. Alloy Compd. 45-52, 526 (2012).

[2] W.J. Buehler, J.V. Gilfrich, and K.C. Weiley, J. Appl. Phys. 34, 1467 (1963).
[3] S. Miyazaki, and K. Otsuka, (edited by H. Funakubo) Gordon and Breach, NewYork, 116 (1987).

[4] L. Delaey, and H. Warlimont, (edited by J. Perkins) (SMEA Perkins), Plenum Press, New York, London, 89 (1975).

[5] H. Funakubo, Gordon and Breach, New York, 1984.

[6] H. Tobushi, E. Pieczyska, S. Gadaj, W.K. Nowacki, K. Hoshio, Y. Makino, Sci. Technol. Adv. Mater. 6, 889 (2005).

[7] M. Dolce, D. Cardone, Int. J. Mech. Sci. 43, 2657 (2001).

[8] E. Cingolani, M. Ahlers, M. Sade, Acta Metall. Mater. 43, 2451 (1995).

[9] K. Bhattacharya, Oxford University Press, New York, (2003). 
[10] T.W. Duering, K.N. Melton, D. Stockel, C.M. Wayman, Butterworth-Heinemann, London, (1990).

[11] Y. Liu, J. Van. Humbeeck, J. Phys. IV. 7, 519 (1997).

[12] C. Tatar, F. Yakuphanoglu, Thermochim. Acta 430, 129 (2005).

[13] Z. Wang, X. Zu, and Y. Fu, International Journal of Smart and Nano Materials 2, 101 (2011).

[14] L. Yong, L. Yulong, K.T. Ramesh, and J.V. Humbeeck, Scripta Mater. 41, 89 (1999).

[15] Y. Zheng, L. Cui, J. Schrooten, Appl. Phys. Lett. 84-1, 31 (2004).

[16] W.M. Huang, Mater. Sci. Eng. A 392, 121 (2005).

[17] T. Kurita, H. Matsumoto, K. Sakamoto, H. Abe, J. Alloy Compd. 400, 92 (2005).

[18] Y. Liu, H. Yang, A. Voigt, Mater. Sci. Eng. A 360, 350 (2003).

[19] S. Ozgen, C. Tatar, Met. Mater. Int. 18, 6, 909 (2012).

[20] R. Lahoz, J.A.Puertolas, J. Alloy Compd. 381, 130 (2004).
[21] C. Tatar, S. Kazanc, Curr. Appl. Phys. 12, 98 (2012).

[22] K. Otsuka, C.M. Wayman, Cambridge Univ. Press, (1998).

[23] D.A. Porter, K.E. Easterling, 2nd ed., Chapman \& Hall, T.J. Press (Padstow), UK (1992).

[24] Y. Huo, X. Zu, Contin. Mech. Therm. 10, 179 (1998).

[25] R. Zengin, Thermochim. Acta, 503-504, 61 (2010).

[26] X.T. Zu, C.F. Zhang, S. Zhu, Y. Huo, Z.G. Wang, L.M. Wang, Mater. Lett. 57, 2099 (2003).

[27] P. Wollants, M. De Bonte, J.R. Roos, Z. Metall. 70, 113 (1979).

[28] R.Y. Umetsu, X. Xu, R. Kainuma, Scripta Mater. 116, 1 (2016).

[29] Y. Liu, A. Mahmud, F. Kursawe, T.H. Nam, J. Alloy Compd. 449, $82(2008)$

[30] L.Yinong, Y. Hong, Smart Mater. Struct. 16, 22 (2007).

[31] C.A. Canbay, A. Aydogdu, Y. Aydogdu, Supercond. Nov. Magn. 24, 871 (2011). 